Check for updates

Health and Social Care Board Northern Ireland

melissa@mtmresearch.com Cite this as: BMJ 2020;369:m2406 http://dx.doi.org/10.1136/bmj.m2406 Published: 19 June 2020

\title{
ESSAY
}

\section{Ethical decision making in a pandemic: where are the voices of vulnerable people?}

The UK government has not and is not following its own ethical principles outlined in its covid-19 guideline for adult social care. This needs to be given urgent priority by the government, policy makers, frontline staff, and the wider public, writes Melissa McCullough

\section{Melissa McCullough ethicist and non-executive director}

As my mother struggled with feeling isolated and lonely during lockdown in her nursing home, I continued to reassure her that she was in the safest place she could be. But, despite being closed to all but essential workers since the beginning of March, a large outbreak of covid-19 occurred in the nursing home. ${ }^{1}$ With a lack of testing available, a shortage of appropriate personal protective equipment (PPE), and an absence of respect and prioritisation, the workers and residents were left to silently spread the virus. Sadly, my mother died shortly after contracting covid-19. ${ }^{2}$

Her death is but one of the numerous lives lost in nursing and care homes around the world; in the UK it is thought that as many as half of covid-19 deaths are occurring in care homes. ${ }^{3}$ As a clinical ethicist, I am uneasy with the UK government's apparent disuse of its own ethical guidelines and how, if it was following them, this catastrophic outcome could have been avoided. As a grieving daughter, I want authorities to do what is right for the most vulnerable people in society who deserve to have their lives valued and protected.

\section{Principles and values}

An ethical framework is a set of principles and values that provide a solid foundation for safe and ethical practice and serve to guide us in acting properly as individuals, in creating responsible organisations and governments, and in promoting ethical societies.

In healthcare ethics, the often cited "four principles" of patient autonomy, beneficence, non-maleficence, and justice have a well established and recognised status in the health and social care fields. ${ }^{4}$ In pandemic planning, however, those principles are shifted to a public health ethics framework, which the vast majority of governments have developed through pandemic planning exercises. These frameworks vary between countries, and probably within countries when put into practice, but largely focus on the greatest outcomes for the population rather than the individual.

The UK government developed and published an ethical framework on 19 March 2020 in relation to covid-19 for adult social care. ${ }^{5}$ This framework was adapted and refreshed from the ethical framework first developed by the Committee on Ethical Aspects of Pandemic Influenza in 2007, which was later revised by the Department of Health and Social Care in 2017. It states: "Equal concern and respect should be given to all individuals, their families and carers, and communities, as well as the professionals and volunteers that we will be relying on to ensure the delivery of our services and ambitions."5

The framework outlines each ethical value and principle and associated actions and best practice when considering and applying them (box 1). The guidance further states: "Each principle must be considered to the extent possible in the context of each circumstance with appropriate risk management and considerations of individual wellbeing, overall public good, and available information and resources." 5

Box 1: Responding to covid-19-the ethical framework for adult social care ${ }^{5}$

Respect

Recognising that every person and their human rights, personal choices, safety, and dignity matter. Reasonableness

Ensuring that decisions are rational, fair, practical, and grounded in appropriate processes, available evidence, and a clear justification.

Minimising harm

Striving to reduce the amount of physical, psychological, social, and economic harm that the outbreak might cause to individuals and communities. In turn, this involves ensuring that individual organisations and society as a whole cope with and recover from it to their best ability. Inclusiveness

Ensuring that people are given a fair opportunity to understand situations, be included in decisions that affect them, and offer their views and challenge. In turn, decisions and actions should aim to minimise inequalities as much as possible.

\section{Accountability}

Holding people, and ourselves, to account for how and which decisions are made. In turn, this requires being transparent about why decisions are made and who is responsible for making and communicating them. Flexibility

Being responsive, able, and willing to adapt when faced with changed or new circumstances. It is vital that this principle is applied to the health and care workforce and wider sector to facilitate agile and collaborative working. Proportionality

Providing support that is proportional to needs and abilities of people, communities, and staff, and the benefits and risks that are identified through decision making processes.

Community 
A commitment to get through the outbreak together by supporting one another and strengthening our communities to the best of our ability.

When considering the current situation of covid-19 deaths in care homes and the community, it is not clear if this guidance has been read or followed.

\section{Respect, reasonability, and inclusion}

The ethical framework states: "In all instances, respect and reasonableness should be used as the fundamental, underpinning principles which guide planning and support judgements." ${ }^{5}$ It stands to reason that had people in care homes and their carers been afforded the right to be involved (inclusiveness) in aspects of planning in the event of a pandemic, they would have overwhelmingly opted to be protected.

A lack of respect exists in failing to help people get what they are entitled to, subject to available resources, and to ensure "that there is a fair judgement and clear justification for any decisions made on prioritisation.” The extent of the loss of life ${ }^{6}$ arising from the lack of protection related to non-prioritisation of PPE and testing for these extremely vulnerable people, along with care staff in poor working conditions and required to work across different care homes, ${ }^{7}$ has infringed on people's human rights and resulted in a dangerous lack of respect for patients and staff.

The guidance states: “Although resources may become stretched, it should be upheld that people with comparable needs should have the same opportunity to have those needs met." The decision to not provide or attempt to ethically allocate proper protection or testing without providing evidence and a clear justification for these actions is unreasonable-as the government has yet to provide evidence of fair processes and a clear justification.

Proportionality requires, among other things, support for those who are asked to take increased risks or face increased burdens, while attempting to minimise these as far as possible; yet, there has been very little minimising of risk in nursing and care homes. ${ }^{7}$ Neglecting to protect residents and their carers means choosing not to minimise their risk of harm and to ignore the risks that they were facing.

Poor working conditions, zero hour contracts, low pay, and little opportunity for professional development have led to high turnover and high numbers of vacancies in essential care work. Now such workers must also endure an increased risk of harm to themselves, their families, and the most vulnerable people in our society because of shortages of PPE and testing.

Our aides, nurses, nursing home carers, and community home care workers, among others, should feel valued and respected by society, and this should be reflected in their pay and working conditions. In turn, the vulnerable and sick people that they care for would also benefit.

\section{Accountability}

Related to respect is a need for accountability and responsibility when things go wrong. We need answers to why healthcare workers and vulnerable people were left unprotected and why this continued for such a long time.

Frontline staff in hospitals, primary care, care homes, and the community have all had to contend with shortages; no one was prepared for the PPE required for this pandemic. But in addition to this, there seems to be a lack of procedural justice in the ethical allocation of the protective gear that we do have. Meanwhile, the government has rejected claims that care homes were forced to take patients with unknown covid-19 status from hospitals without proper support. ${ }^{8}$

A sad truth is that a decade of chronic underfunding of social care has been the main contributor to this situation, leading to the inequitable treatment and poor working conditions in the care sector, which in turn has rendered the government's own ethical guidance impossible to implement.

The principle of accountability requires transparency about how and which decisions need to be made and on what basis, accepting responsibility for your actions, and being willing to be answerable to the outcomes of the choices, decisions, and actions made. We've heard the UK prime minister, Boris Johnson, admit that he "bitterly regrets" the care home crisis, ${ }^{9}$ but as yet no one has accepted the responsibility or explained how such decisions were made.

We still do not fully know who was responsible for and how decisions were (and still are being) made regarding resource allocation in the care home and community care sectors. Was there a decision making framework for making PPE and testing allocations? Did the public have a say in the ethical framework that might now be in practice to decide who should get the scarce yet lifesaving PPE? We have seen guidance from the National Institute for Health and Care Excellence on allocating ventilators and intensive care beds in clinical care $\mathrm{e}^{10}$ but nothing that provides detail on how a decision was taken to leave the most vulnerable people in society and their carers unprotected.

All decisions that are made need to have a justification showing how and why they were made, ensuring that appropriate records of those decisions are being kept. We the public should be asking to see those records. Now is the time for transparency, accountability, and equality-it is unethical to simply suggest that we wait until it is a subject of some expensive inquiry in the near future. We must advocate for our most vulnerable people and demand the accountability, respect, reasonableness, and inclusiveness they deserve as a human right.

\section{Biography}

$\overline{\text { Melissa McCullough is a clinical ethicist and currently a visiting academic }}$ at the Royal College of Surgeons in Ireland. She has worked as an academic in ethics, law, and professionalism in medical schools in Ireland and the UK and has been a ministerial appointed non-executive director for the Health and Social Care Board in Northern Ireland since 2009, a panel assessor and chair for undergraduate medical education with the Irish Medical Council and a recent member of the clinical governance board at Doctor Care Anywhere.

Patient involvement: My mother, Donna Penrose, who died on 7 April from covid-19 in her nursing home provided the patient input and the impetus for me to write this as a clinical ethicist.

Competing interests: We have read and understood BMJ policy on declaration of interests and have the following interests to declare: None

Ferriss S. When nursing home workers feel like "lambs led to slaughter." 2020 Apr 22. Centre for Public Integrity. https://publicintegrity.org/health/coronavirus-and-inequality/when-nursinghome-workers-feel-like-lambs-led-to-slaughter/

2 McCullough M. Platform: we must treat our health and social care workers with dignity and respect. Irish News 2020 Apr 14. https://www.irishnews.com/news/northernirelandnews/2020/04/14/news/platform-we-must-treat-our-health-and-social-care-workers-with-dignityand-respect-1900912/

3 Booth R. Testing for coronavirus in UK care homes a "complete system failure." Guardian 2020 May 12. https://www.theguardian.com/society/2020/may/12/testing-coronavirus-uk-care-homescomplete-system-failure

Beauchamp T, Childress J. Principles of biomedical ethics. 7th ed. Oxford University Press, 2013. Department of Health and Social Care. Responding to covid-19: the ethical framework for adult social care. 19 March 2020. https://www.gov.uk/government/publications/covid-19-ethicalframework-for-adult-social-care/responding-to-covid-19-the-ethical-framework-for-adult-socialcare 
6 Office for National Statistics. Dataset: number of deaths in care homes notified to the Care Quality Commission, England. 12 May 2020 https://www.ons.gov.uk/peoplepopulationandcommunity/birthsdeathsandmarriages/deaths/datasets/numberofdeathsincarehomesnotifiedtothecarequalitycommissionengland

7 Grey S, MacAskill A. Special report: in shielding its hospitals from covid-19, Britain left many of the weakest exposed. Reuters London 2020 May 5. https://uk.reuters.com/article/uk-healthcoronavirus-britain-elderly-sp/special-report-in-shielding-its-hospitals-from-covid-19-britain-leftmany-of-the-weakest-exposed-idUKKBN22H2El

8 Downing Street rejects claims care homes forced to take coronavirus patients without proper support. Guardian 2020 May 19. https://www.theguardian.com/world/live/2020/may/19/ukcoronavirus-live-latest-updates?page=with:block-5ec3d26c8f08a1782fa7d7c1\#block$5 e c 3 d 26 c 8 f 08 a 1782 f a 7 d 7 c 1$

9 Triggle N. Coronavirus: Boris Johnson "bitterly regrets" care home crisis. BBC News 2020 May 6. https://www.bbc.co.uk/news/uk-politics-52547869

10 National Institute for Health and Care Excellence. Covid-19 rapid guideline: critical care in adults. NICE guideline [NG159]. 20 March 2020. https:/www.nice.org.uk/guidance/ng159 